\title{
REVISITING THE JONSWAP BOTTOM FRICTION FORMULATION
}

\author{
Gerbrant van Vledder ${ }^{12}$, Marcel Zijlema ${ }^{1}$ and Leo Holthuijsen ${ }^{1}$
}

\begin{abstract}
The derivation of the JONSWAP bottom friction for wind-driven seas is revisited. This is motivated by the fact that in the literature two different values for the corresponding coefficient are recommended; one value applicable for swell conditions and a significantly higher value for wind-driven sea conditions. The value applicable for winddriven seas was originally determined by Bouws and Komen (1983) who studied the source term balance of a remarkably stationary storm in shallow water. We used a more accurate interpretation of these observations by hindcasting this storm with the third-generation wave model SWAN using state-of-the-art source terms. In addition, we compare wave model results with measurements in the Dutch Wadden Sea and with parametric growth curves, some of which were obtained in Lake George, Australia. The results strongly suggest that the lower bottom friction value of $C_{b}=0.038 \mathrm{~m}^{2} \mathrm{~s}^{-3}$ is applicable for both wind-sea and swell conditions.
\end{abstract}

Keywords: Wave modelling, bottom friction, TMA scaling, SWAN, JONSWAP, North Sea

\section{INTRODUCTION}

Bottom friction is one of the physical mechanisms for the dissipation of wave energy in shallow water. Various parameterizations exist which can all be expressed in the following form:

$$
S_{b f r}(f, \theta)=-C_{b} E(f, \theta) \sigma^{2} /\left(g^{2} \sinh ^{2} k d\right)
$$

in which $C_{\mathrm{b}}$ is a bottom friction coefficient, $d$ the water depth and $k$ the wave number. For swell conditions observed during the JONSWAP experiment, Hasselmann et al. (1973) found $C_{\mathrm{b}}=0.038$ $\mathrm{m}^{2} \mathrm{~s}^{-3}$, whereas for fully developed wind-sea conditions in shallow water Bouws and Komen (1983) found $C_{\mathrm{b}}=0.067 \mathrm{~m}^{2} \mathrm{~s}^{-3}$. This difference suggests that the one value should be used for swell conditions and the other value for wind-sea conditions. These values are correspondingly chosen as default value in the SWAN wave model (Booij et al., 1999). However, the large difference in value and the failure of SWAN to properly hindcast low-frequency energy in shallow water motivated us to investigate the origin of the high parameter value.

We started this investigation by revisiting the derivation of Bouws and Komen (1983). In addition we performed a hindcast of the same storm that formed the basis of their analysis. Further, we inspected results of hindcast studies in the Dutch Wadden Sea and we performed a shallow water growth curve analysis, which we compared with measurements from Lake George, Australia.

\section{REVISITING THE BOUWS-KOMEN APROACH}

Bouws and Komen (1983) studied the wave energy balance during the 3 January 1976 storm in the southern North Sea. Wave observations were collected with a Waverider buoy located near the island of Texel, see Figure 1 for a situation sketch. This storm was rather stationary during 12 hours. The stationary wave situation was characterized by a significant wave height of about $7.6 \mathrm{~m}$ and a peak period of about $11.6 \mathrm{~s}$. According to Bouws and Komen (1983) the estimated wind speed $U_{10}$ in the area of the wave measurements was about $25 \mathrm{~m} / \mathrm{s}$ and the local water depth $30 \mathrm{~m}$. Measured wave data (time series of surface elevation) are only available for a short period during the final build-up and peak of the storm. The hourly variation of the measured significant wave height $H_{\mathrm{m} 0}$ and spectral wave period $T_{\mathrm{m}-1,0}$ is shown in Figure 2. These parameters were obtained from the variance spectra.

Bouws and Komen (1983) reconstructed the energy balance using a representative wave spectrum and using 1983-state-of-the-art parameterizations for wind input, whitecapping, and exact non-linear four-wave interactions. The average of the measured spectra during the stationary period was used as the representative spectrum for their analysis. The balance was supplemented with an estimate of the effect of geographic propagation using TMA-scaling arguments (see Bouws et al. 1985) over a 1Dtransect of $100 \mathrm{~km}$ to the north-west. The depth along this transect varied from $30 \mathrm{~m}$ to $45 \mathrm{~m}$ to the north-west.

\footnotetext{
${ }^{1}$ Delft University of Technology, Delft, Netherlands, g.p.vanvledder@tudelft.nl

${ }^{2}$ Arcadis / Alkyon, Marknesse, Netherlands.
} 


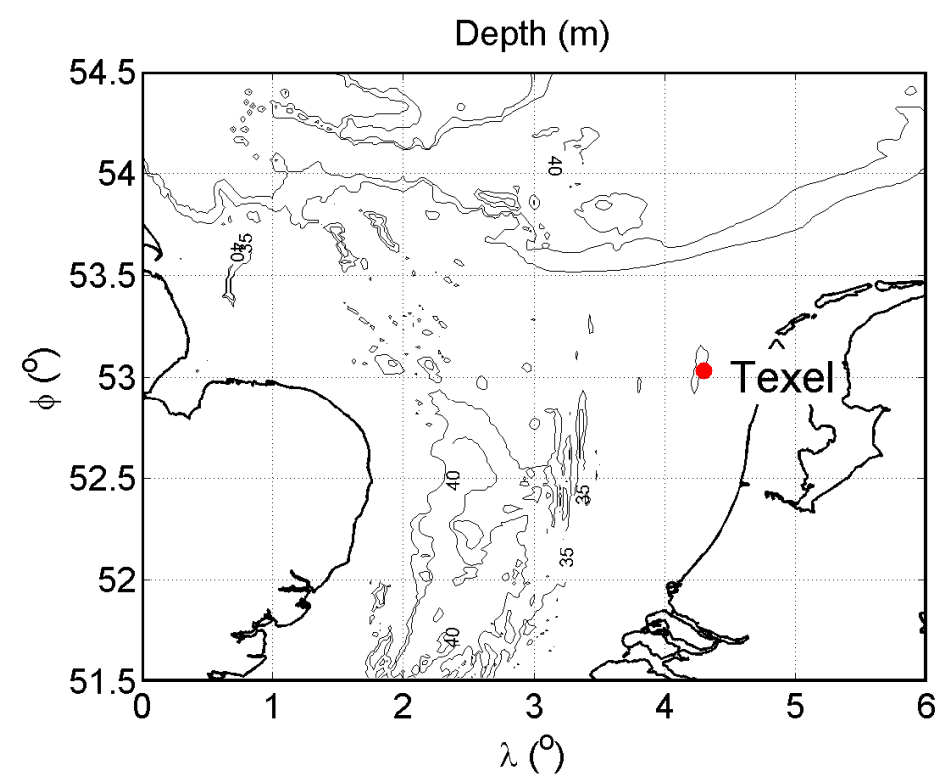

Figure 1. Situation sketch of the southern North Sea and Texel measurement location (red dot).
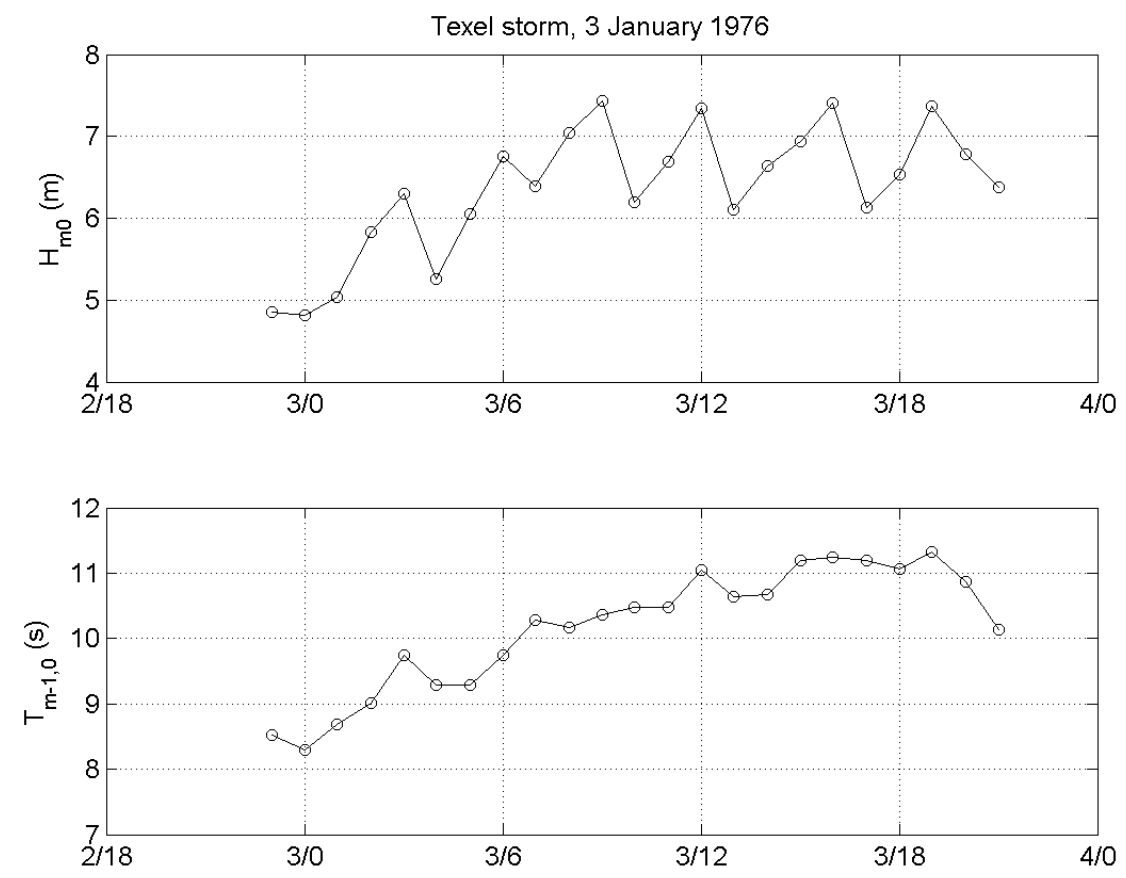

Figure 2. Observed variation of the significant wave height $H_{\mathrm{m} 0}$ and spectral period $T_{\mathrm{m}-1,0}$ during the storm of 3 Jan. 1976. Numbers along $x$-axis indicate day/hour in January 1976.

Close inspection of all the steps and assumptions in the above sketched procedure revealed a number of possible uncertainties. The first uncertainty is the assumed wind speed during the stationary interval; it was estimated to be $25 \mathrm{~m} / \mathrm{s}$. As no wind measurements were carried out at the buoy location, it was deduced from the three nearest land-based stations; IJmuiden, Den Helder and Terschelling. To eliminate local land roughness effects it was transformed to open water with the method of Wieringa (1976). As described in Bouws (1979) a roughness length $z_{0}=2 \times 10^{-4}$ was applied in this transformation. This value seems rather low (it corresponds to a wind drag coefficient of $1.4 \times 10^{-3}$ ). Using a higher 
roughness length will probably lead to lower wind speeds at the buoy location and subsequently to a lower bottom friction coefficient to close the energy balance.

A second uncertainty is the estimate of the contribution of the propagation term to the energy balance. Bouws and Komen (1983) considered a one-dimensional transect with a depth varying from 45 $\mathrm{m}, 100 \mathrm{~km}$ up-wind, to $30 \mathrm{~m}$ at the buoy location. The variation of the shallow water wave spectra was estimated using TMA scaling (Bouws et al., 1985). This scaling is a simple parametric method to transform wave spectra from deep to shallow water. However, it includes effects of dissipation so that the effect of dissipation was double counted in their analysis. Further, applying the TMA scaling along the 1D-transect implies that 2D-effects like refraction are not included.

With hindsight we can state that a third uncertainty of the analysis of Bouws and Komen (1983) is their choice of source terms for wind input and whitecapping. Presently, improved source terms are available that may well lead to a different source term balance for this storm.

Instead of investigating the source term balance in a similar but improved way as done by Bouws and Komen (1983), we are now in a position to perform a full hindcast of the Jan. 1976 storm using the state-of-the-art wave model (SWAN; Booij et al., 1999) and re-analysed wind fields varying in time and space. In this way the wind is better estimated, source terms are up-dated and 2D-propagation effects are properly accounted for.

\section{HINDCAST OF THE JANUARY 1976 STORM}

The January 1976 storm was hindcast with the SWAN model on a spherical 501 (east-west) by 651 (north-south) grid covering the North Sea. The geographic resolution was $\Delta \lambda=0.025^{\circ}$ and $\Delta \varphi=0.0167^{\circ}$ (corresponding to $1.857 \mathrm{~km}$ in north-south direction and varying from $1.62 \mathrm{~km}$ in the north to about 2.72 in the south in east-west direction). The extent of the computational grid and the depth with respect to mean sea level is shown in Figure 3. The location of the Texel measurement location is indicated with a black/yellow dot.

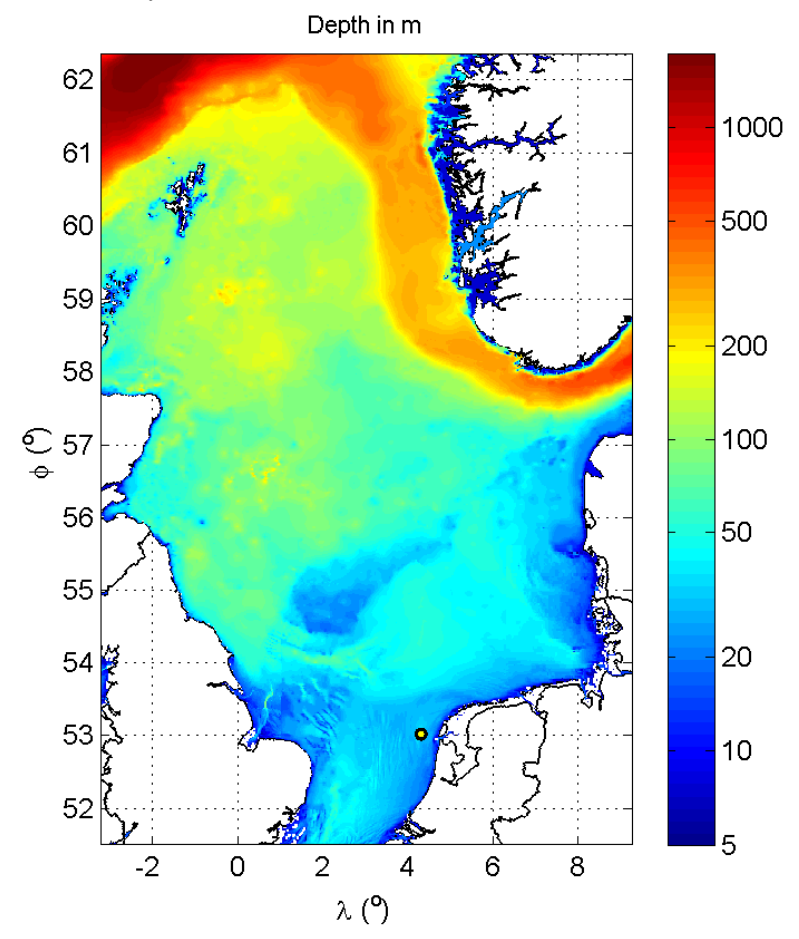

Figure 3. Extent of computational grid and bathymetry of the SWAN model for the North Sea. Depths in meters with respect to mean sea level. The measurement location Texel is indicated with a black/yellow dot.

Hourly wind fields were provided by the Royal Netherlands Meteorological Institute (KNMI). Due to its date of occurrence, no accurate wind fields were available for this storm. As the KNMI was also interested in this study, it carried out a re-analysis of this storm. This was achieved by blending a HIRLAM model in large-scale wind fields from the ECMWF. The HIRLAM model was run on a polar 
shifted grid and the model wind components were interpolated to the SWAN computational grid. An example of a shifted HIRLAM wind field and the outline of the computational SWAN grid are shown in Figure 4.

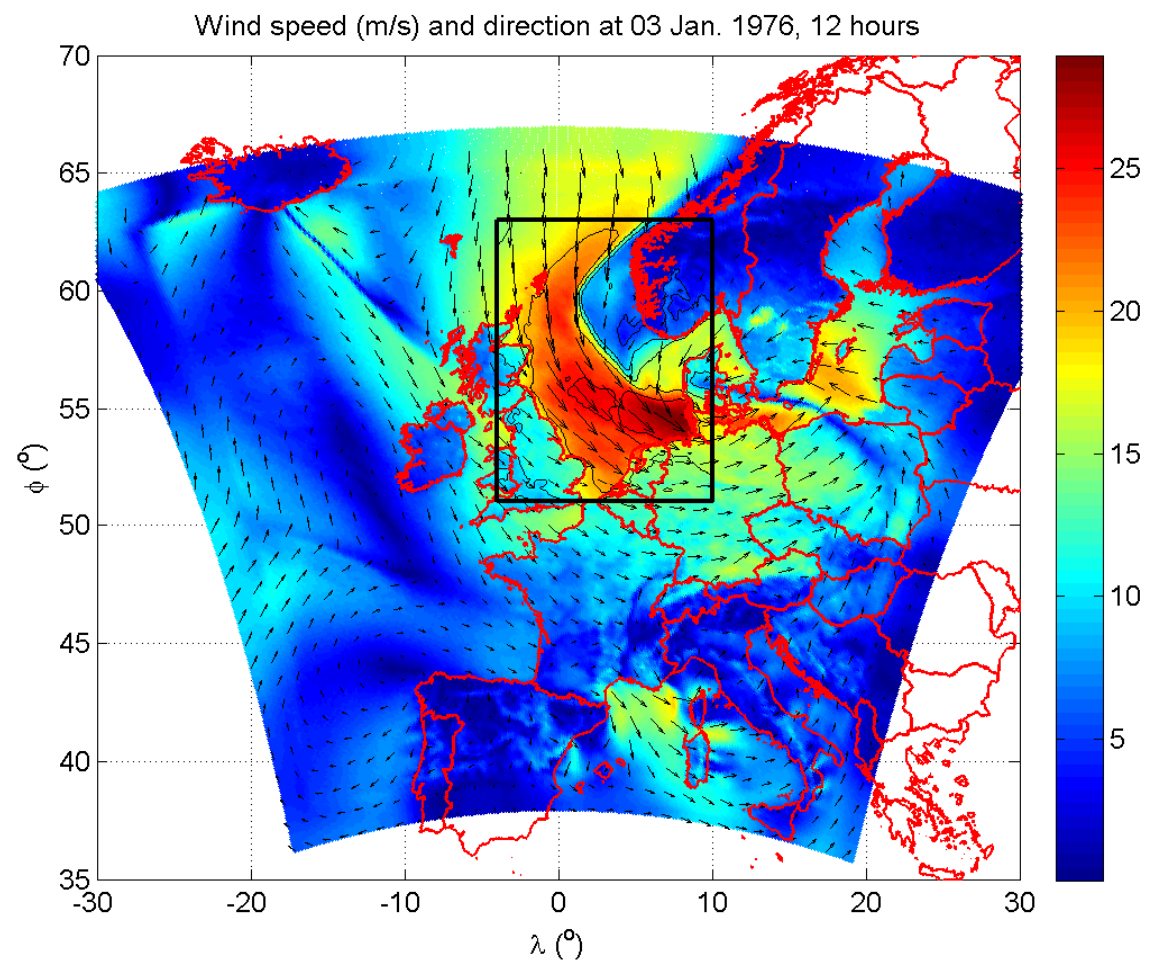

Figure 4. HIRLAM wind field and outline of SWAN computational grid for 3 Jan. 1976, 12:00 hours. Colors indicate wind speed in $\mathrm{m} / \mathrm{s}$, arrow indicate the direction to.

Figure 5 shows the computed wind speed at $10 \mathrm{~m}$ elevation at the Texel buoy location. It can be seen that it is generally lower than $25 \mathrm{~m} / \mathrm{s}$ as inferred by Bouws and Komen (1983).

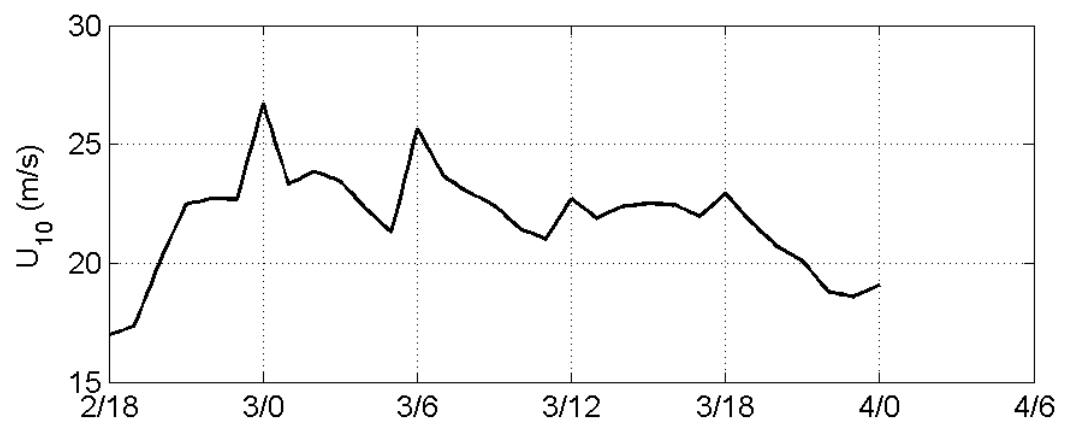

Figure 5. The average wind speed at $10 \mathrm{~m}$ elevation at the buoy location obtained from the HIRLAM model.

The SWAN model was run in non-stationary mode with a time step of 10 minutes using a start-up time of 2 days, starting on Jan. 1, 1976, 1:00 hours. The effect of growth and decay of wave energy was modelled using the formulation of Komen et al. (1984) in which we applied the so-called n2.0 setting for whitecapping (Rogers et al., 2003; Zijlema, 2009). For the four-wave interactions we applied the DIA approach of Hasselmann et al. (1985) instead of the exact transfer rate as applied by Bouws and Komen (1983). The reason for this choice is that we aim to obtain a bottom friction coefficient for operational settings of a spectral wave model. Dissipation by surf breaking was parameterized with the Battjes-Janssen (1978) approach using $\gamma=0.73$. 
Special attention was paid to the parameterisation of the drag coefficient as a function wind speed $U_{10}$. The commonly used parameterisation of the drag coefficient in SWAN is due to Wu (1982):

$$
C_{d}=\left\{\begin{array}{cccc}
1.2875 \times 10^{-3} & \text { for } & U_{10}<7.5 & \mathrm{~m} / \mathrm{s} \\
\left(0.8+0.065 U_{10}\right) \times 10^{-3} & \text { for } & U_{10} \geq 7.5 & \mathrm{~m} / \mathrm{s}
\end{array}\right.
$$

However, inspection of various data sets gives us reason to suspect that these values are too high for higher wind speeds. We therefore applied the parameterisation of Large and Pond (1981) yielding $13 \%$ lower drag coefficient for a wind speed of $25 \mathrm{~m} / \mathrm{s}$ than the one by $\mathrm{Wu}$ (1982). The expression of Large and Pond (1981) is given by:

$$
C_{d}=\left\{\begin{array}{cccc}
1.2 \times 10^{-3} & \text { for } & U_{10}<11 & \mathrm{~m} / \mathrm{s} \\
\left(0.49+0.065 U_{10}\right) \times 10^{-3} & \text { for } & U_{10} \geq 11 & \mathrm{~m} / \mathrm{s}
\end{array}\right.
$$

The storm was hindcast using both the lower and the higher values of JONSWAP bottom friction coefficient to assess which values gives the best agreement with measurements. For the comparison we computed the significant wave height $H_{\mathrm{m} 0}$ and the spectral periods $T_{\mathrm{m}-1,0}$ and $T_{\mathrm{m} 01}$. Figure 5 shows the results of the comparison. Remarkably, the observed cyclic variation of the significant wave height, and to a lesser extent also for the spectral period $T_{\mathrm{m} 02}$, is not captured by the wave model. This may be related to a shortcoming of the wind fields. The main finding of this hindcast is that for all three parameters the SWAN model run with the lower bottom friction value of $C_{\mathrm{b}}=0.038 \mathrm{~m}^{2} \mathrm{~s}^{-3}$ gives the best agreement with measurements. One other result of our simulations was that surf breaking was negligible compared those of the other source terms.
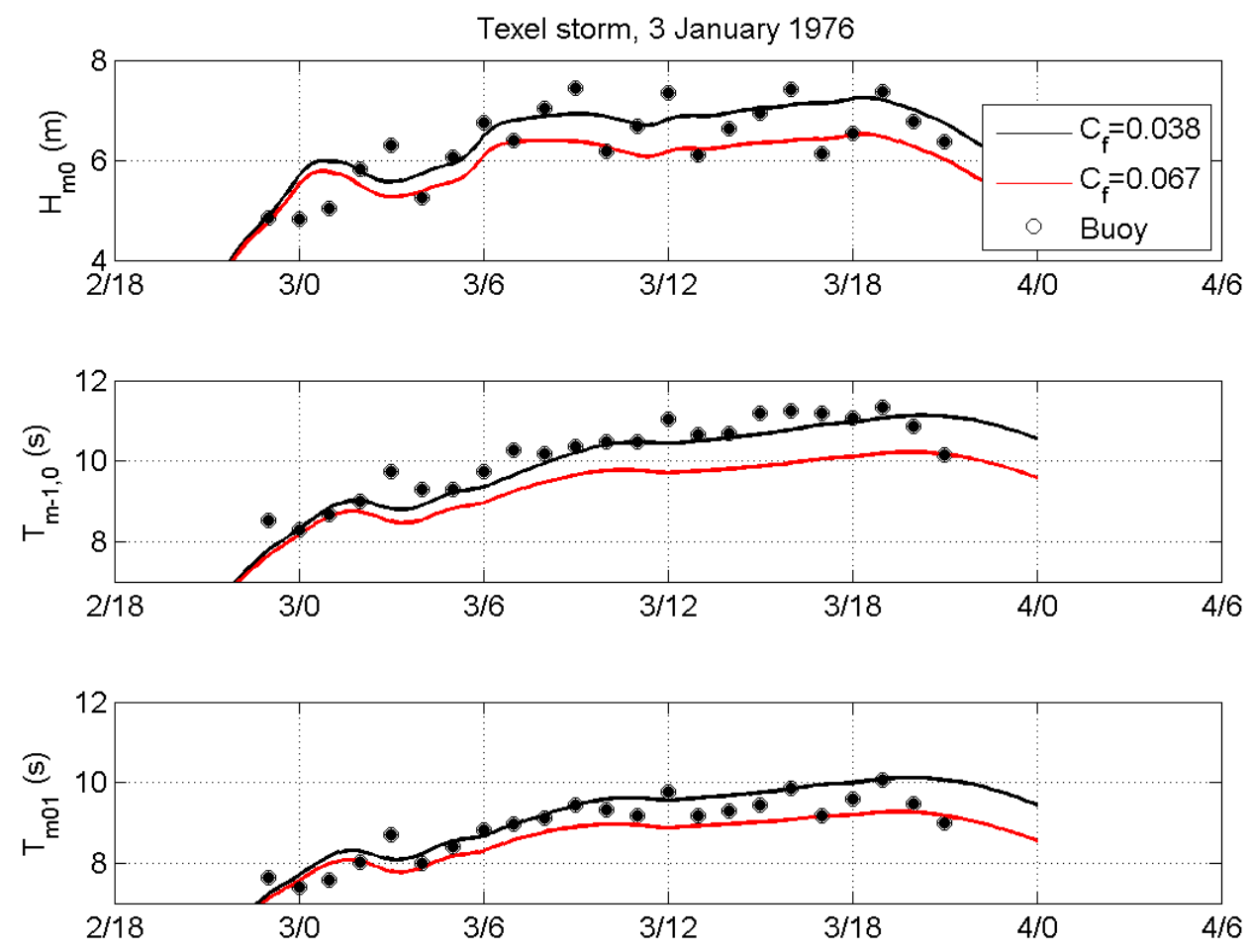

Figure 6. Comparison of computed and measured significant wave height $\boldsymbol{H}_{\mathrm{m} 0}$ and spectral periods $\mathrm{T}_{\mathrm{m}-1,0}$ and $T_{\mathrm{m} 01}$ for the Texel storm using the JONSWAP bottom friction coefficients of $C_{\mathrm{b}}=0.038 \mathrm{~m}^{2} \mathrm{~s}^{-3}$ (black line) and $C_{b}=0.067 \mathrm{~m}^{2} \mathrm{~s}^{-3}$ (red line). Measurements (black dots). 


\section{GENERALIZED SHALLOW WATER RESULTS}

Young and Verhagen (1996) observed fully developed wave conditions in Lake George which they presented in the traditional dimensionless form of dimensionless wave height and period versus dimensionless depth. We performed SWAN model computations for a constant wind speed of $U_{10}=10$ $\mathrm{m} / \mathrm{s}$ (the wind speed during the observations of Young and Verhagen, 1996) to reproduce the parametric results of Young and Verhagen (1996). The model computations were performed with the low and the high value for the bottom friction coefficient. Figure 7 shows the comparison of our model results with those of Young and Verhagen (1996), but also with those reported by Bretschneider (1973) and Holthuijsen (1980). The left panel of Figure 7 shows the results for the higher value of the friction coefficient $C_{\mathrm{b}}=0.067 \mathrm{~m}^{2} \mathrm{~s}^{-3}$. The right panel shows the results for the lower value of the friction coefficient $C_{\mathrm{b}}=0.038 \mathrm{~m}^{2} \mathrm{~s}^{-3}$. The results in Figure 7 show that these parameterizations are better reproduced with SWAN using $C_{\mathrm{b}}=0.038 \mathrm{~m}^{2} \mathrm{~s}^{-3}$ rather than $C_{\mathrm{b}}=0.067 \mathrm{~m}^{2} \mathrm{~s}^{-3}$. In these computations the drag parameterisation of $\mathrm{Wu}(1982)$ was used.

\section{WAVE HINDCASTS IN THE WADDEN SEA AND LIVERPOOL BAY}

Zijlema (2009) applied the SWAN model in the Wadden Sea (southern North Sea) and compared his hindcast results of a winter storm of 2007 with buoy measurements in the tidal inlet of Ameland. Figure 8 shows a comparison of the measured and computed wave spectra at two buoy locations in the tidal inlet of Ameland. He found considerably better results, in particular for low frequencies, by using the value $C_{\mathrm{b}}=0.038 \mathrm{~m}^{2} \mathrm{~s}^{-3}$ observed during JONSWAP. Van Vledder et al. (2009) confirmed these findings with a similar hindcast of the 9 November 2009 storm in the eastern Wadden Sea. For the determination of the Hydraulic Boundary Conditions of the sea dikes along the Dutch Wadden Sea, the Rijswaterstaat Centre for Water Management will apply the SWAN model. Prior to applying this model, it was calibrated by Deltares (2009) against a large amount of shallow water wave data, including data from the Wadden Sea. One of their results is that the JONSWAP bottom friction coefficient can best be set at $C_{\mathrm{b}}=0.038 \mathrm{~m}^{2} \mathrm{~s}^{-3}$. Also in these computations the drag parameterisation of $\mathrm{Wu}(1982)$ was applied.
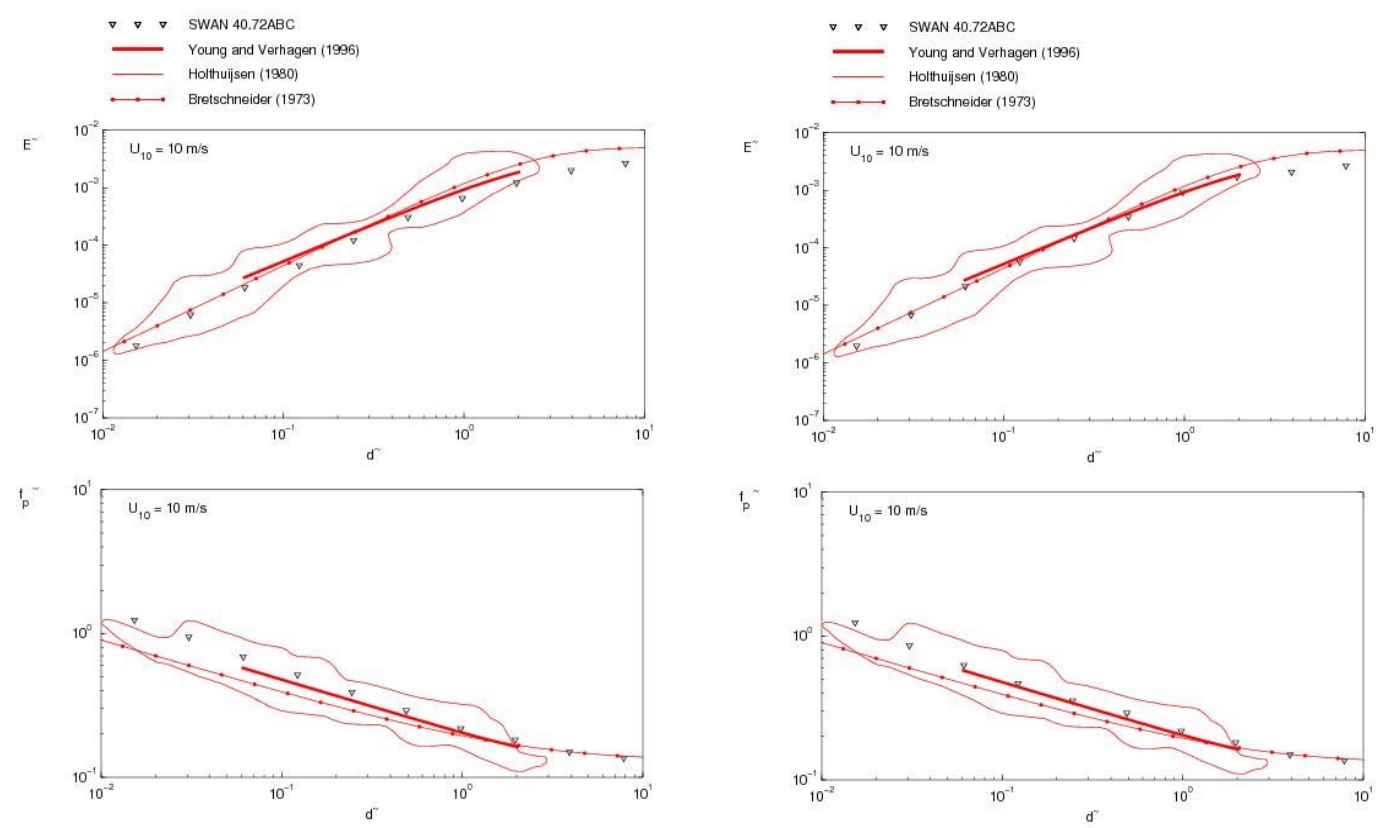

Figure 7. Comparison of SWAN model results (triangles) for shallow water against parametric growth curves obtained in Lake George (Young and Verhagen, 1996). Results for the JONSWAP bottom friction coefficient of $C_{b}=0.067 \mathrm{~m}^{2} \mathrm{~s}^{-3}$ (left panel) and $C_{\mathrm{b}}=0.038 \mathrm{~m}^{2} \mathrm{~s}^{-3}$ (right panel). 
Brown (2010) performed a hindcast of a strong surge event in Liverpool Bay using both the WAM and SWAN model, both coupled to the POLCOMS flow model. The best results were obtained when the default JONSWAP bottom friction value of $C_{\mathrm{b}}=0.067 \mathrm{~m}^{2} \mathrm{~s}^{-3}$ was replaced by the lower (swell) value of $C_{\mathrm{b}}=0.038 \mathrm{~m}^{2} \mathrm{~s}^{-3}$.
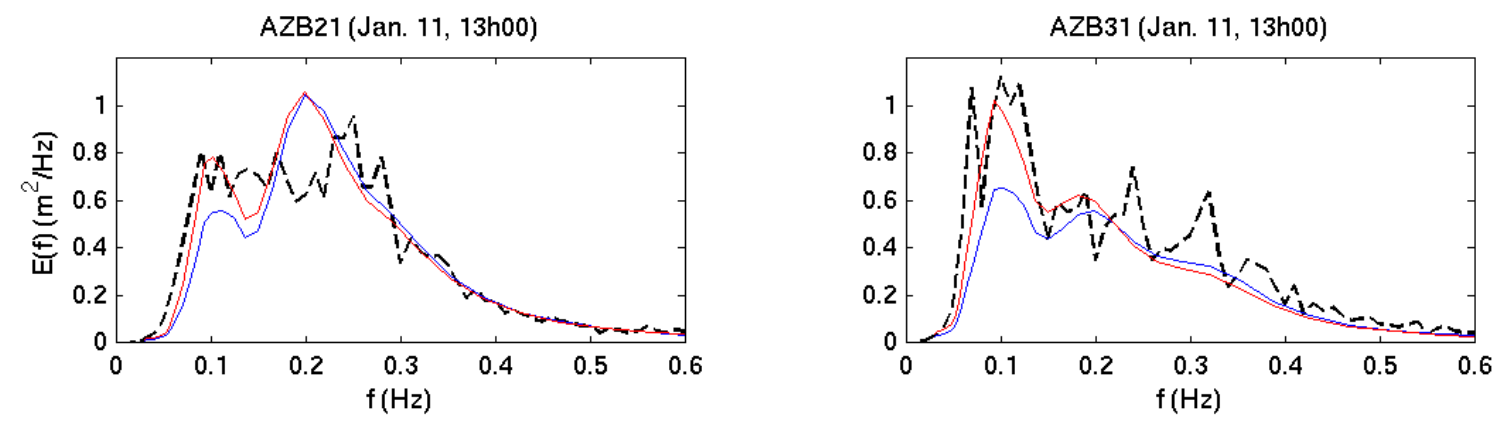

Figure 8. Observed and computed wave spectra at two buoy locations in the tidal inlet of Ameland during the storm of January 11, 2007. Measurement (black, dashed), default SWAN (blue, $C_{b}=0.067 \mathrm{~m}^{2} \mathrm{~s}^{-3}$ ), SWAN with reduced bottom friction (red, $C_{\mathrm{b}}=0.038 \mathrm{~m}^{2} \mathrm{~s}^{-3}$ ).

\section{DISCUSSION}

The existence of two rather different values of the JONSWAP bottom friction coefficient has been taken for granted for well over 25 years. This is remarkable as there has been no theoretical foundation for the existence of this difference. Only in the last years, wave modelers have obtained indications that the higher value for wind-sea conditions might be too high. With the present analysis we have shown that the high value for wind-sea conditions might be based on an approach that can be replaced by a more accurate model estimate. This reflects the fact that our knowledge of wave physics has improved considerably during the last thirty years. Applying this knowledge is one of the reasons that we reach a different conclusion than Bouws and Komen (1983), although based on the same observations.

\section{CONCLUSION}

A reanalysis of the work of Bouws and Komen (1983), the hindcast of the Texel storm, the reproduction of the generalized observations of Young and Verhagen (1996) and the hindcast and calibration results of Zijlema (2009), Van Vledder et al., (2009), Deltares (2010) and Brown (2010) all suggest that for sandy bottoms, the bottom friction coefficient $C_{\mathrm{b}}=0.067 \mathrm{~m}^{2} \mathrm{~s}^{-3}$ is too high and that much better results can be obtained with the value $C_{\mathrm{b}}=0.038 \mathrm{~m}^{2} \mathrm{~s}^{-3}$ observed during JONSWAP. Our results also suggest that this value can be used for a wide range of bottom material and independent of whether the waves are wind-sea or swell.

\section{ACKNOWLEDGMENTS}

The help of Frank Lantsheer, Hans de Vries and Evert Bouws of the Royal Netherlands Meteorological Institute (KNMI) for providing the wind fields and wave data of the January 1976 storm is greatly appreciated. Further, wave measurements in the Dutch Waddensea were obtained in the framework of the SBW (Strength and Loads on Water Defenses) project commissioned by the Rijkswaterstaat Centre for Water Management in the Netherlands.

\section{REFERENCES}

Battjes, J.A. and J.P.F.M. Janssen, 1978: Energy loss and set-up due to breaking of random waves. Proc. 16th Int. Conf. on Coastal Engineering, ASCE, 569-587.

Booij, N., R.C. Ris, and L.H. Holthuijsen, 1999: A third-generation wave prediction model for coastal regions, Part I, Model description and validation .J. Geoph. Res, Vol. 104, C4, 7649-7666.

Bouws, E., 1979: Spectra of extreme wave conditions in the Southern North Sea considering the influence of water depth. Proc. Conf. on Sea Climatology. Paris, 1979: Collection Colloquia at Seminars, Vol. 34, 51-69. 
Bouws, E, and G.J. Komen, 1983: On the balance between growth and dissipation in an extreme, depthlimited wind-sea in the southern North Sea. J. Phys. Oceanogr., Vol. 13, 1653-1658.

Bouws, E., H. Günther, W. Rosenthal and C.L. Vincent, 1985: Similarity of the wind wave spectrum in finite depth water. 1. Spectral form. J. Geophys. Res., Vol. 90, C1, 975-986.

Bretschneider, 1973: See SPM, 1973.

Brown, J., 2010: A case study of combined wave and water levels under storm conditions using WAM and SWAN in a shallow water application. In press Ocean Modelling.

Deltares, 2010: SWAN Calibration and Validation for HBC2011, Report 1200103-020.

Hasselmann, K, et al., 1973: Measurements of wind-wave growth and swell decay during the Joint North Sea Wave Project (JONSWAP), Deutch. Hydrogr. Z. Suppl. A8, 12, 95 pp.

Hasselmann, S., K. Hasselmann, K., J.H. Allender and T.P. Barnett, 1985: Computations and parameterizations of the nonlinear energy transfer in a gravity wave spectrum. Part II: parameterizations of the nonlinear transfer for application in wave models. J. Phys. Oceanogr., Vol. 15 (11): 1378-1391.

Holthuijsen, L.H., 1980: Methods of wave prediction, part I and II (Methoden voor golfvoorspelling, deel I en II, in Dutch), Technical Advisory Commission against Inundation (Technische Adviescommissie voor de Waterkeringen, in Dutch), Den Haag, The Netherlands.

Large, W. G., and S. Pond, 1981: Open ocean momentum flux measurements in moderate to strong winds. J. Phys. Ocean., Vol. 11, 324-481.

Rogers, W.E., P.A. Hwang, and D.W. Wang, 2003: Investigation of wave growth and decay in the SWAN model: three regional-scale applications. J. Phys. Oceanogr., Vol. 33, 366-389.

SPM, 1973: Shore Protection Manual, U.S. Army Coastal Engineering Research Center.

Van Vledder, G.Ph., J. Adema, O.R. Koop, F.J.M. Enet and A.J. van der Westhuysen, 2009: Lowfrequency wind wave penetration in a tidal inlet system during a severe winter storm. Proc. 11th Int. Workshop on Wave Hindcasting and Forecasting, Halifax, Canada.

Wieringa, J., 1976: An objective exposure correction method for average wind speeds measured at a sheltered location. Quart. J. Roy. Soc., Vol. 102, 241-253.

Wu, J., 1982: Wind-stress coefficients over sea surface from breeze to hurricane, J. Geophys. Res., Vol. 87, C12, 9704-9706.

Young, I.R. and L.A. Verhagen, 1996: The growth of fetch limited waves in water of finite depth. Part 1: Total energy and peak frequency. Coastal Engineering, Vol. 29, 47-78.

Zijlema, M., 2009: Multiscale simulations using unstructured mesh SWAN model for wave hindcasting in the Dutch Wadden Sea. Paper 2, Coastal Dynamics, Tokyo, Japan. 